\title{
TINGKAT KEPATUHAN PENGOBATANDAN PERUBAHAN GAYA HIDUP SEHAT, PASIEN HIPERTENSI DI WILAYAH KERJA PUSKESMAS TEGALLALANG I, BALI TAHUN 2014
}

\author{
Andrew Valentinus Purwanto, Komang Ayu Kartika Sari \\ Program Studi Pendidikan Dokter, Fakultas Kedokteran, Universitas Udayana
}

\begin{abstract}
ABSTRAK
Hipertensi merupakan salah satu faktor penyebab terjadinya penyakit jantung, stroke, dan kematian. Menurut Riskesdas 2013, terdapat 25,8\% penduduk berusia $\geq 18$ tahun yang menderita hipertensi di Indonesia dan 19,9\% di Bali. Di Puskesmas Tegallalang I terdapat 620 kasus hipertensi pada tahun 2013 dan hipertensi/stroke menjadi penyebab pertama kematian tahun 2013 di Puskesmas Tegallalang I. Adapun tujuan dari penelitian ini untuk mengetahui gambaran tingkat kepatuhan pengobatan dan perubahan gaya hidup sehat pasien hipertensi di wilayah kerja Puskesmas Tegallalang I. Penelitian ini menggunakan metode cross sectional deskriptif. Data diperoleh dengan cara wawancara menggunakan kuesioner pada 41 sampel. Dari hasil analisis didapatkan 87,8\% memiliki tingkat kepatuhan yang rendah, $12,2 \%$ memiliki tingkat kepatuhan sedang, dan tidak didapatkan tingkat kepatuhan yang tinggi. Didapatkan pula $39 \%$ mengalami penurunan konsumsi rokok, 4,9\% mengalami penurunan konsumsi alkohol, 36,6\% mengalami penurunan konsumsi kopi, 4,9\% mengalami penurunan durasi menonton, 31,7\% mengalami peningkatan jumlah olah raga dalam 1 minggu, dan 34,1\% mengalami peningkatan durasi berolahraga. Sebagian besar subyek penelitian memiliki tingkat kepatuhan yang rendah.
\end{abstract}

Kata Kunci:hipertensi, kepatuhan, perubahan gaya hidup

\section{MEDICATION COMPLIANCE AND LIFESTYLE MODIFICATION IN HYPERTENSION PATIENT IN TEGALLALANG IPRIMARY HEALTH CAREWORKING AREA, BALI 2014}

\begin{abstract}
Hypertension is one of the factor that cause heart disease, stroke, and death. Based on Riskesdas 2013 , there were $25,8 \%$ people $\geq 18$ years old who suffered from hypertension in Indonesia and $19,9 \%$ in Bali. There were 620 cases of hypertension in Puskesmas Tegallalang I and became the first cause of death in 2013 in Puskesmas Tegallalang I. The purpose of this study to know the overview of medication compliance and lifestyle modification in hypertensive patient in working area of Puskesmas Tegallalang I. This study is using descriptive cross sectional model. Datas were obtained by interview using a questionnaire to 41 sample. Based on the result of analysis, $87,8 \%$ have low compliance, $12,2 \%$ have medium compliance, and no one has high compliance. The result also shows $39 \%$ people decreased in consumption of tobaco, 4,9\% decreased in consumption of alcohol, $36,6 \%$ decreased in consumption of coffee, $4,9 \%$ decreased in duration of watching television, $31,7 \%$ increase the frequency of sport in a week, and $34,1 \%$ increased in duration of sport. Most of the subject of this study have a low medication compliance.
\end{abstract}

Keywords: hypertension, medication compliance, lifestyle modification 


\section{PENDAHULUAN}

Hipertensi merupakan salah satu kontributor penyebab penyakit dan kematian yang dapat dicegah. Menurut WHO, tekanan darah pada orang dengan umur > 18 tahun diklasifikasikan berdasarkan rata-rata dari dua atau lebih pengukuran yang dilakukan dengan tepat pada dua atau lebih kunjungan. ${ }^{1}$ Menurut JNC 7, klasifikasi tekanan darah dibagi menjadi empat yaitu normal $(<120 / 80 \mathrm{mmHg})$, prehipertensi (sistolik 120-139 mmHg atau diastolik 80-89 $\mathrm{mmHg}$ ), hipertensi derajat 1 (sistolik 140-159 $\mathrm{mmHg}$ atau diastolik $90-99 \mathrm{mmHg}$ ), dan hipertensi derajat 2 (sistolik $\geq 160 \mathrm{mmHg}$ atau diastolik $\geq 100$ $\mathrm{mmHg})^{2}$

Hipertensi merupakan faktor risiko utama penyebab penyakit jantung dan stroke. Dilaporkan bahwa hipertensi menduduki peringkat keempat sebagai penyebab kematian prematur di negara maju dan peringkat ketujuh di negara berkembang. Laporan terbaru menunjukkan bahwa hampir 1 milyar orang menderita hipertensi pada tahun 2000 dan diprediksi meningkat menjadi 1,56 milyar di tahun 2025 . $^{3}$ Data dari CDC tahun 2013 menunjukkan bahwa prevalensi hipertensi di Amerika konsisten dalam kurun waktu 10 tahun kebelakang. Selain itu, prevalensi hipertensi paling tinggi terdapat pada kelompok umur $\geq 65$ tahun pada tahun 2007 hingga 2010. ${ }^{4}$

Sedangkan di Indonesia sendiri, menurut data Riskesdas 2013, prevalensi hipertensi di Indonesia yang didapat melalui pengukuran pada umur $\geq 18$ tahun sebesar 25,8 persen. Prevalensi tertinggi terdapat di Bangka Belitung 30,9\%), diikuti Kalimantan Selatan (30,8\%), Kalimantan Timur (29,6\%), dan Jawa Barat (29,4\%). Di Bali, prevalensi penderita hipertensi yang didapat melalui pengukuran pada umur $\geq 18$ tahun mencapai 19,9\%. Meskipun Bali menduduki peringkat kedua dari bawah, tetapi masalah hipertensi tetap menjadi fokus perhatian mengingat penyakit lain yang dapat ditimbulkan akibat hipertensi. ${ }^{5}$

Berdasarkan data dari profil Puskesmas Tegallalang I tahun 2013, hipertensi menduduki peringkat delapan dari 10 besar penyakit yang berada di wilayah kerja Puskesmas Tegallalang I. Terdapat 620 kasus hipertensi yang tercatat di profil Puskesmas Tegallalang I tahun 2013.
Sedangkan jumlah penduduk yang berada di wilayah kerja Puskesmas Tegallalang I mencapai total 24.968 jiwa dari empat desa yang ada, dengan penduduk yang berumur $\geq 20$ tahun mencapai 18149 jiwa. ${ }^{6}$ Selain itu, hipertensi/stroke menduduki peringkat pertama penyebab kematian dengan jumlah 50 orang, sedangkan penyebab kematian akibat gangguan jantung mencapai 10 orang. ${ }^{7} \mathrm{Hal}$ ini perlu mendapat perhatian khusus, mengingat pada tahap awal hampir tidak terdapat keluhan. Hipertensi merupakan faktor independen penyebab penyakit kardiovaskular, serebrovaskular, dan kematian.

Hipertensi dibagi menjadi dua, yaitu hipertensi primer dan sekunder. Hipertensi primer merupakan hipertensi yang tidak diketahui penyebabnya atau disebut juga hipertensi esensial atau idiopatik, sedangkan yang diketahui penyebabnya disebut hipertensi sekunder. Sejumlah 85-90\% hipertensi merupakan hipertensi primer, hanya sebagian kecil yang merupakan hipertensi sekunder. Pada tahap awal pasien tidak terdapat keluhan pada pasien hipertensi. Jika terdapat gejala, maka umumnya yang dirasakan yaitu berdebar-debar, rasa melayang (dizzy) akibat peningkatan tekanan darah itu sendiri, sesak napas, sakit dada akibat kelainan pada sistem jantung, dan lain-lain. Mekanisme patofisiologis utama meliputi aktivasi sistem saraf simpatis dan sistem renin-angiotensin-aldosteron. Disfungsi endotel, peningkatan reaktifitas vaskular, dan remodeling vaskular merupakan penyebab kenaikan tekanan darah. ${ }^{8}$

Peningkatan prevalensi penyakit kardiovaskular dan hipertensi yang terjadi pada negara berkembang berhubungan dengan perubahan gaya hidup. ${ }^{9}$ Faktor risiko hipertensi dabat dibagi menjadi tidak dapat dikontrol dan yang terkontrol. Keturunan, jenis kelamin, dan umur merupakan faktor risiko yang tidak dapat dikontrol. Sedangkan kegemukan, kurang olahraga, merokok, konsumsi alkohol dan garam merupakan faktor risiko yang dapat dikontrol. Penderita hipertensi yang sangat heterogen membuktikan bahwa hipertensi diderita oleh orang dari berbagai subkelompok berisiko didalam masyarakat. Hal ini juga menandakan bahwa hipertensi dipengaruhi oleh faktor risiko ganda, 
baik eksogen (rokok, nutrisi, dan lain-lain) maupun endogen (neurotransmitter, hormon, genetik). ${ }^{10}$

Pengobatan hipertensi yang baik sangat penting dalam mengurangi morbiditas, mortalitas, dan mengkontrol biaya kesehatan yang berkaitan dengan penyakit ini. Hanya saja, upaya pengobatan yang dilakukan sering terhambat kendala kepatuhan pasien dalam mengkonsumsi obat. Ketidakpatuhan pasien untuk meminum obat yang telah diresepkan telah menjadi masalah utama di dunia. WHO menyebutkan bahwa kepatuhan pengobatan pada pasien kronik hanya berkisar $50 \%$ di negara maju dan lebih buruk di negara berkembang. Ketidakpatuhan pasien untuk meminum obat dapat menyebabkan hipertensi menjadi tidak terkontrol. Hal tersebut mengakibatkan peningkatan beban penyakit.

Penelitian-penelitian mengenai kepatuhan pengobatan yang dilakukan sebelumnya menunjukkan hasil yang tidak konsisten. Hasil yang didapatkan dari dua studi menunjukkan bahwa orang tua dan pasien wanita cenderung kurang patuh. ${ }^{11,12}$ Pada studi yang lain, didapatkan bahwa orang tua cenderung lebih patuh dibanding orang muda dan wanita lebih patuh secara signifikan dibandingkan laki-laki dengan hipertensi yang baru terdeteksi. ${ }^{13}$

Tujuan penelitian ini adalah untuk mengetahui gambaran tingkat kepatuhan pengobatan dan perubahan gaya hidup sehat pasien hipertensi di wilayah kerja Puskesmas Tegallalang I. Dengan diketahuinya gambaran tingkat kepatuhan pengobatan dan perubahan gaya hidup sehat, maka diharapkan dapat membantu sebagai dasar dala, penetapan program-program yang bertujuan untuk mengurangi dampak jangka panjang dari hipertensi.

\section{METODE PENELITIAN}

Penelitian ini menggunakan rancangan penelitian cross sectional deskriptif, yaitu dilakukan satu kali pengumpulan data untuk mengetahui tingkat kepatuhan pengobatan dan perubahan gaya hidup sehat pasien hipertensipada kelompok umur 20-44 tahun di wilayah kerja Puskesmas Tegallalang I, Kabupaten Gianyar. Penelitian ini dilaksanakan pada bulan Maret 2014 hingga April 2014. Populasi penelitian ini adalah semua penderita hipertensi pada kelompok umur 20-44 tahun yang berada di wilayah kerja Puskesmas Tegallalang I.

Kriteria inklusi dalam penelitian ini adalah subyek dengan umur 20-44 tahun, didiagnosis hipertensi dalam rentang waktu Januari 2013 sampai dengan Februari 2014 dan sedang menjalani pengobatan hipertensi, dan data nama dan alamat tersedia di puskesmas. Kriteria eksklusi yaitu subyek berada di luar wilayah kerja Puskesmas Tegallalang I dan subyek dengan data nama dan alamat tidak tersedia di Puskesmas Tegallalang I.

Pada penelitian ini digunakan metode total sampling untuk mendapatkan sampel yang dibutuhkan. Sampel didapatkan dari buku register Puskesmas Tegallalang I. Besar sampel ditentukan dengan rumus Snedecor dan Cochran (1967). Pada penghitungan sampel ini dikehendaki tingkat kepercayaan 95\% dan ketepatan absolut yang diinginkan sebesar 10\%. Proporsi yang dicari sebelumnya tidak diketahui, maka dipergunakan nilai $P$ adalah $0,50, Z \alpha=1,96, d=15 \%$ sehingga didapatkan besar sampel 43 sampel. ${ }^{14}$ Karena jumlah populasi pasien hipertensi pada kelompok umur 20-44 tahun di tempat penelitian kurang dari 10.000 orang, maka sampel untuk penelitian ini dikoreksi dengan cara sebagai berikut:

$$
n_{1}=\frac{n}{1+n / N}=\frac{43}{1+43 / 1939}=42
$$

Berdasarkan perhitungan diatas, didapatkan jumlah sampel minimal dalam penelitian ini adalah sebanyak 42. Berdasarkan data yang terdapat dalam buku register Puskesmas Tegallalang I, maka jumlah sampel yang digunakan pada penelitian ini berjumlah 41 orang. Sampel yang terpilih selanjutnya ditetapkan sebagai responden untuk memperoleh data-data yang diperlukan untuk penelitian ini.

Adapun variabel - variabel dalam penelitian ini meliputi jumlah obat yang dikonsumsi, penyakit penyerta, umur, jenis kelamin, riwayat keluarga, tingkat kepatuhan pengobatan, serta perubahan gaya hidup pasien seperti konsumsi rokok, alkohol, kopi, durasi menonton,dan olahraga sebelum diagnosis dan setelah diagnosis hipertensi.

Cara pengumpulan data dalam penelitian ini berupa pengisian kuisioner yang dilakukan oleh pengumpul data dengan cara menanyakan 
langsung kepada responden. Data yang terkumpul kemudian diolah dan dianalisis dengan menggunakan program komputer, meliputi data entry, recoding, dan análisis data. Analisis data dilakukan secara deskriptif menggunakan program komputer dan dijabarkan dalam bentuk naratif atau tabel untuk mengetahui tingkat kepatuhan pengobatan dan perubahan gaya hidup sehat pasien hipertensi di wilayah kerja Puskesmas Tegallalang I.

HASIL

Karakteristik Pasien Hipertensi Usia 20-44 Tahun di Wilayah Kerja Puskesmas Tegallalang I

Pada karakteristik penduduk yang dijabarkan antara lain jenis kelamin, umur, riwayat keluarga yang hipertensi, penyakit penyerta, dan jumlah obat yang sedang dikonsumsi (Tabel 1).

Berdasarkan hasil penelitian yang meliputi 41 subyek penduduk usia 20-44 tahun, didapatkan bahwa jumlah subyek yang berjenis kelamin laki- laki lebih banyak $(56,1 \%)$ dibandingkan subyek yang berjenis kelamin perempuan $(43,9 \%)$. Umur subyek terbanyak terdapat pada kelompok umur 35-44 tahun. Dari 41 subyek, 36 subyek $(87,8 \%)$ memiliki riwayat keluarga yang menderita hipertensi, sedangkan sisanya (12,2\%) tidak memiliki riwayat keluarga yang menderita hipertensi. Berdasarkan penyakit penyerta, 19,5\% subyek memiliki riwayat penyakit penyerta, sedangkan sisanya $80,5 \%$ tidak memiliki penyakit penyerta. Berdasarkan jumlah obat yang sedang dikonsumsi, 33 subyek $(80,5 \%)$ hanya mengkonsumsi satu jenis obat, 6 subyek $(14,6 \%)$ mengkonsumsi dua jenis obat, dan 2 subyek (4,9\%) mengkonsumsi tiga jenis obat.

Tingkat Kepatuhan Pasien Hipertensi Usia 20-44 Tahun di Wilayah Kerja Puskesmas Tegallalang I

Tingkat kepatuhan dibagi menjadi rendah, sedang, dan tinggi menggunakan Morisky Medication Adherence Scale - 8 (MMAS-8) (Tabel2)

Tabel 1. Karakteristik Penduduk Usia 20-44 Tahun di Wilayah Kerja Puskesmas Tegallalang I, Gianyar

\begin{tabular}{lll}
\hline Karakteristik Penduduk & Frekuensi & Persen (\%) \\
\hline Jenis Kelamin & 23 & 56,1 \\
Laki-laki & 18 & 43,9 \\
Perempuan & & \\
Umur & 18 & 43,9 \\
20-34 & 23 & 56,1 \\
35-44 & & 87,8 \\
Riwayat Keluarga & 36 & 12,2 \\
Positif & 5 & \\
Negatif & & 19,5 \\
Penyakit Penyerta & 8 & 80,5 \\
Ada & 33 & \\
Tidak Ada & & 80,5 \\
Jumlah Obat Yang Sedang Dikonsumsi & 33 & 14,6 \\
1 & 6 & 4,9 \\
2 & 2 &
\end{tabular}

Tabel 2. Tingkat Kepatuhan Pasien Hipertensi Usia 20-44 Tahun

\begin{tabular}{|c|c|c|c|}
\hline \multicolumn{2}{|c|}{ Variabel } & Frekuensi & Persen (\%) \\
\hline \multirow{3}{*}{ Tingkat Kepatuhan } & Rendah & 36 & 87,8 \\
\hline & Sedang & 5 & 12,2 \\
\hline & Tinggi & 0 & 0 \\
\hline
\end{tabular}




\section{Total}

Tabel 2 menunjukkan bahwa jumlah subyek dengan tingkat kepatuhan pengobatan kurang paling banyak, yaitu berjumlah 36 orang $(87,8 \%)$ dibandingkan dengan subyek dengan tingkat kepatuhan sedang yang berjumlah 5 orang $(12,2 \%)$. Tidak ada subyek yang masuk kategori tingkat kepatuhan tinggi (0\%).

\section{1}

100

Tabel 3. Tingkat Kepatuhan Pengobatan Berdasarkan Umur, Jenis Kelamin, Penyakit Penyerta, dan Jumlah Obat yang Sedang Dikonsumsi

\begin{tabular}{lllcccc}
\hline \multirow{2}{*}{ No } & \multirow{2}{*}{ Variabel } & \multicolumn{2}{c}{ Rendah } & \multicolumn{2}{c}{ Sedang } \\
\cline { 4 - 7 } & & & $\mathbf{f}$ & $\mathbf{\%}$ & $\mathbf{f}$ & $\%$ \\
\hline 1 & Umur & $20-34$ & 17 & 94,4 & 1 & 5,6 \\
& & $35-44$ & 19 & 82,6 & 4 & 17,4 \\
\hline 2 & \multirow{2}{*}{ Jenis Kelamin } & Laki-Laki & 22 & 95,7 & 1 & 4,3 \\
& & Perempuan & 14 & 77,8 & 4 & 22,2 \\
\hline 3 & Penyakit Penyerta & Ada & 6 & 75 & 2 & 25 \\
& & Tidak Ada & 30 & 90,9 & 3 & 9,1 \\
\hline 4 & Jumlah & 1 & 30 & 90,9 & 3 & 9,1 \\
& Dikonsumsi & 2 & 4 & 66,7 & 2 & 33,3 \\
& & 3 & 2 & 100 & 0 & 0 \\
\hline
\end{tabular}

sedangkan 4 subyek $(17,4 \%)$ memiliki tingkat kepatuhan sedang.

Tabel 3 juga menunjukkan bahwa pada laki-laki, 22 subyek (95,7\%) memiliki tingkat kepatuhan rendah dan 1 subyek (4,3\%) memiliki tingkat kepatuhan sedang. Pada perempuan, 14 subyek $(77,8 \%)$ memiliki tingkat kepatuhan rendah dan 4 subyek $(22,2 \%)$ memiliki tingkat kepatuhan sedang.

Dari tabel 3 juga terlihat bahwa dari 8 subyek yang memiliki penyakit penyerta, 6 subyek (75\%) memiliki tingkat kepatuhan rendah, dan 2 subyek (25\%) memiliki tingkat kepatuhan sedang. Sedangkan dari 33 subyek tanpa penyakit penyerta, 30 subyek (90,9\%) memiliki tingkat kepatuhan rendah dan 3 subyek $(9,1 \%)$ memiliki tingkat kepatuhan sedang.
Berdasarkan tabel 3 diketahui bahwa pada kelompok umur 20-34 tahun, sebanyak 17 subyek $(94,4 \%)$ memiliki tingkat kepatuhan rendah, sedangkan 1 subyek (5,6\%) memiliki tingkat kepatuhan sedang. Pada kelompok umur 35-44 tahun, sebanyak 19 subyek (82,6\%) memiliki tingkat kepatuhan rendah,
Berdasarkan tabel 3, pada kelompok dengan jumlah obat yang sedang dikonsumsi sebanyak 1 , 90,9\% subyek memiliki kepatuhan rendah dan 9,1\% memiliki tingkat kepatuhan sedang. Pada kelompok dengan jumlah obat yang sedang dikonsumsi sebanyak 2, 66,7\% subyek memiliki tingkat kepatuhan rendah dan 33,3\% subyek memiliki tingkat kepatuhan sedang. Pada kelompok dengan jumlah obat yang sedang dikonsumsi sebanyak 3, 100\% subyek memiliki tingkat kepatuhan rendah.

\section{Perubahan Gaya Hidup Sehat Pasien Hipertensi Usia 20-44 Tahun di Wilayah Kerja Puskesmas Tegallalang I \\ Berdasarkan hasil penelitian yang melibatkan 41 subyek, diketahui 16 orang}

Tabel 4. Perubahan Gaya Hidup Sehat Pasien Hipertensi Usia 20-44 Tahun

\begin{tabular}{lll}
\hline Variabel & Frekuensi & Persen (\%) \\
\hline Konsumsi Rokok & & \\
Penurunan & 16 & 39 \\
Tetap & 6 & 14,6 \\
Peningkatan & 0 & 0
\end{tabular}




\begin{tabular}{|c|c|c|}
\hline Tidak Merokok & 19 & 46,3 \\
\hline \multicolumn{3}{|l|}{ Konsumsi Alkohol } \\
\hline Penurunan & 2 & 4,9 \\
\hline Tetap & 2 & 4,9 \\
\hline Peningkatan & 0 & 0 \\
\hline Tidak Mengkonsumsi Alkohol & 37 & 90,2 \\
\hline \multicolumn{3}{|l|}{ Konsumsi Kopi } \\
\hline Penurunan & 15 & 36,6 \\
\hline Tetap & 24 & 58,5 \\
\hline Peningkatan & 0 & 0 \\
\hline Tidak Mengkonsumsi Kopi & 2 & 4,9 \\
\hline \multicolumn{3}{|c|}{ Durasi Menonton TV/Depan Layar Komputer } \\
\hline Penurunan & 2 & 4,9 \\
\hline Tetap & 39 & 95,1 \\
\hline Peningkatan & 0 & 0 \\
\hline Tidak Menonton & 0 & 0 \\
\hline \multicolumn{3}{|l|}{ Jumlah Olahraga Dalam 1 Minggu } \\
\hline Meningkat & 13 & 31,7 \\
\hline Tetap & 7 & 17,1 \\
\hline Menurun & 0 & 0 \\
\hline Tidak Berolahraga & 21 & 51,2 \\
\hline \multicolumn{3}{|l|}{ Durasi Berolahraga } \\
\hline Meningkat & 14 & 34,1 \\
\hline Tetap & 6 & 14,6 \\
\hline Menurun & 0 & 0 \\
\hline Tidak Berolahraga & 21 & 51,2 \\
\hline
\end{tabular}

(39\%) mengalami penurunan jumlah konsumsi rokok. Sebanyak 6 orang $(14,6 \%)$ tidak mengalami perubahan jumlah konsumsi rokok, dan tidak ada yang mengalami peningkatan jumlah konsumsi rokok. Diketahui bahwa sebagian besar subyek $(46,3 \%)$ tidak merokok. Sebagian besar subyek tidak mengkonsumsi alkohol $(90,2 \%)$, sedangkan sisanya mengalami penurunan $(4,9 \%)$ dan tidak mengalami perubahan jumlah konsumsi alkohol (4,9\%). Dilihat dari segi konsumsi kopi, sebanyak 15 subyek $(36,6 \%)$ mengalami penurunan jumlah konsumsi kopi. Sebanyak 24 subyek (58,5\%) tidak mengalami perubahan jumlah konsumsi kopi, dan 2 subyek $(4,9 \%)$ tidak mengkonsumsi kopi.

Berdasarkan durasi menonton TV/depan layar komputer, sebagian besar subyek $(95,1 \%)$ tidak mengalami perubahan durasi menonton dan 4,9\% mengalami penurunan durasi menonton. Dari tabel 4 diketahui bahwa 13 subyek $(31,7 \%)$ mengalami peningkatan jumlah olahraga yang dilakukan dalam satu minggu dan 7\% tidak mengalami perubahan jumlah olahraga. Tetapi, sebagian besar subyek tidak melakukan olahraga (51,2\%). Dilihat dari segi durasi olahraga, 14 subyek (34,1\%) mengalami peningkatan durasi berolahraga. Sebanyak 6 subyek $(14,6 \%)$ berolahraga dengan durasi yang tetap baik sebelum diagnosis maupun setelah diagnosis. Sebanyak 21 subyek $(51,2 \%)$ tidak berolahraga.

\section{DISKUSI}

Karakteristik Pasien Hipertensi Usia 20-44 Tahun di Wilayah Kerja Puskesmas Tegallalang I

Jumlah sampel penelitian ini adalah 41 orang pasien hipertensi usia 20-44 tahun yang berada di wilayah kerja Puskesmas Tegallalang I, Kabupaten Gianyar. Berdasarkan hasil penelitian yang meliputi 41 subyek pasien hipertensi usia 20-44 tahun, didapatkan bahwa jumlah subyek yang berjenis kelamin laki-laki lebih banyak $(56,1 \%)$ 
dibandingkan perempuan (43,9\%) dimana sebagian besar subyek berumur 40-44 tahun. Umur memegang peranan penting dalam terjadinya hipertensi. Pada proses penuaan, terjadi penurunan visko-elastisitas pembuluh darah yang progresif, peningkatan resiko atherosklerosis, serta hipertropi dan sklerosis arteri dan arteriol. ${ }^{15}$ Selain itu, juga bisa terjadi kekakuan pembuluh darah dan peningkatan aktivitas renin.Proses penuaan juga mengakibatkan penurunan fungsi fisiologis tubuh, yang dapat menyebabkan fungsi eksresi ginjal terganggu dan mengakibatkan retensi garam. Hal ini akan berimplikasi pada terjadinya peningkatan tekanan darah. ${ }^{16}$

Pada 87,8\% subyek diketahui bahwa mereka memiliki riwayat keluarga dengan hipertensi, sedangkan $12,2 \%$ diketahui tidak memiliki riwayat keluarga yang menderita hipertensi. Hipertensi termasuk dalam penyakit dimana genetik juga memegang peranan dalam timbulnya penyakit ini. ${ }^{17}$ Hanya saja, peran genetik dalam timbulnya hipertensi sangatlah kompleks. Tidak ada satu gen pun yang memainkan peranan paling penting dalam menyebabkan hipertensi. Hipertensi dapat terjadi akibat interaksi antar gen.Lebih dari 50 gen sudah dipelajari kaitannya dengan hipertensi, dan jumlah tersebut akan semakin meningkat. ${ }^{17}$

Tingkat Kepatuhan Pasien Hipertensi Usia 20-44 Tahun di Wilayah Kerja Puskesmas Tegallalang I, Gianyar

Dari 41 subyek pada penelitian ini, didapatkan 36 subyek $(87, \%)$ memiliki tingkat kepatuhan rendah, 5 subyek $(12,2 \%)$ memiliki tingkat kepatuhan sedang, dan tidak ada yang memiliki tingkat kepatuhan tinggi. Tingkat kepatuhan pada penelitian ini diukur menggunakan kuesioner MMAS-8 dan dibagi menjadi tinggi (0), sedang (1-2), dan rendah (>2). Kuesioner MMAS-8 merupakan modifikasi dari MMAS. Pada MMAS hanya terdapat 4 pertanyaan, sedangkan pada MMAS-8 terdapat 4 pertanyaan tambahan mengenai perilaku kepatuhan dan memiliki atribut psikometrik yang lebih baik. Keuntungan digunakannya MMAS adalah pertanyaan yang digunakan sederhana dan mudah dalam penghitungan nilai. ${ }^{18}$

Menurut Almas et al, tingkat kepatuhan dipengaruhi oleh kelalaian, efek samping yang ditimbulkan, jumlah obat yang diminum, tidak diberitahu dengan baik, dan finansial. ${ }^{19}$ Selain itu, faktor-faktor yang mempengaruhi kepatuhann pengobatan dapat dikelompokkan menjadi patient-related factors, treatment-related factors, healthcare system-related factors, socioeconomicrelated factors, dan disease-related factors. ${ }^{20}$

Pada penelitian ini ditemukan bahwa pasien dengan umur yang lebih tua cenderung memiliki tingkat kepatuhan yang lebih tinggi. Hal ini dapat dilihat dari hasil penelitian yang didapatkan. pada kelompok umur 20-24 tahun dan 25-29 tahun, $100 \%$ memiliki tingkat kepatuhan rendah. Pada kelompok umur 30-34 tahun didapatkan 92,3\% memiliki tingkat kepatuhan rendah dan 7,7\% memiliki tingkat kepatuhan sedang. Pada kelompok umur 35-39 tahun ditemukan 87,5\% memiliki tingkat kepatuhan rendah dan 12,5\% memiliki tingkat kepatuhan sedang. Pada kelompok umur 40-44 tahun, $80 \%$ memiliki tingkat kepatuhan rendah dan $20 \%$ memiliki tingkat kepatuhan sedang. Menurut Doggrel, umur tidak menjadi faktor penting yang mempengaruhi kepatuhan pengobatan. ${ }^{21}$ Penelitian menunjukkan bahwa kepatuhan pengobatan dapat meningkat maupun menurun seiring dengan bertambahnya umur. Penelitian yang dilakukan oleh Park et al menunjukkan bahwa tingkat kepatuhan pengobatan pasien arthritis rheumatoid meningkat seiring dengan bertambahnya umur. ${ }^{22}$ Penelitian lain oleh Monane et al pada pasien hipertensi juga menunjukkan hal yang sama. ${ }^{23}$ Tetapi, penelitian yang dilakukan oleh Benner et al menunjukkan hasil yang berbeda. Pada pasien pengguna statin, tingkat kepatuhan menurun seiring dengan bertambahnya umur. ${ }^{24}$

Jika melihat tingkat kepatuhan menurut jenis kelamin, pada penelitia ini diketahui bahwa perempuan cenderung lebih patuh dibanding lakilaki. Penelitian yang dilakukan oleh Joho juga menemukan hasil yang serupa, dimana hasil yang didapatkan yaitu perempuan memiliki tingkat kepatuhan pengobatan dibanding laki-laki $(63,2 \%$ vs $45,8 \%$; $\mathrm{P}<0.05) .^{25}$

Jika melihat tingkat kepatuhan menurut penyakit penyerta, terlihat bahwa tingkat kepatuhan menjadi lebih tinggi jika terdapat penyakit penyerta. Tetapi, perlu dilihat bahwa jumlah subyek yang memiliki penyakit penyerta 
lebih sedikit dibanding jumlah subyek yang tidak memiliki penyakit penyerta. Begitu pula jika melihat tingkat kepatuhan menurut jumlah obat yang sedang dikonsumsi.

\section{Perubahan Gaya Hidup Sehat Pasien Hipertensi Usia 20-44 Tahun di Wilayah Kerja Puskesmas Tegallalang I}

Perubahan gaya hidup sehat dilihat dari enam aspek, yaitu konsumsi rokok, konsumsi alkohol, konsumsi kopi, durasi menonton, jumlah olahraga dalam satu minggu, dan durasi berolahraga. Tujuan dilakukan pencarian data ini adalah untuk mnegetahui perubahan gaya hidup penderita sebelum diagnosis dan sesudah diagnosis. Berdasarkan hasil penelitian yang melibatkan 41 subyek, diketahui bahwa 16 subyek (39\%) mengalami penurunan jumlah konsumsi rokok, $14,6 \%$ tetap, dan 46,3\% tidak merokok. Merokok merupakan salah satu faktor resiko timbulnya hipertensi.

Dari aspek konsumsi alkohol, sebagian besar subyek tidak mengkonsumsi alkohol (90,2\%). Sebanyak 2 subyek mengalami penurunan jumlah konsumsi (4,9\%), dan sisanya mengkonsumsi alkohol dalam jumlah yang tetap. Konsumsi alkohol merupakan salah satu faktor terjadinya hipertensi, meskipun penelitian menyebutkan bahwa konsumsi alkohol dalam jumlah yang tidak berlebihan dapat berfungsi sebagai agen protektif. Tetapi, asupan yang tinggi berkaitan dengan resiko terjadinya berbagai macam penyakit. Karena itu, sebagian besar otoritas medis dan buku pedoman tidak menganjurkan alkohol sebagai penurun resiko penyakit kardiovaskular. Sehingga, jumlah asupan alkohol pada penderita hipertensi harus diberikan pengawasan.

Sebanyak 15 subyek (36,6\%) mengalami penurunan jumlah konsumsi kopi, 24 subyek $(58,5 \%)$ tidak mengalami perubahan jumlah konsumsi kopi, dan 2 subyek (4,9\%) tidak mengkonsumsi kopi. Studi yang dilakukan Jenner di Australia menunjukkan bahwa konsumsi kopi berkaitan dengan kenaikan tekanan darah dalam waktu 6 tahun. $^{26}$ Studi prospektif lain yang melibatkan 1.017 subjek juga menunjukkan asosiasi yang positif dengan tekanan darah sistolik $(0,19 \mathrm{mmHg})$ dan diastolik $(0,27 \mathrm{mmHg})$ per gelas per hari. ${ }^{27}$
Aktifitas fisik merupakan salah satu gaya hidup yang dianjurkan bagi penderita hipertensi. Dari penelitian, sebanyak $51,2 \%$ subyek mengaku tidak berolahraga. Tetapi, pekerjaan yang dilakukan subyek termasuk dalam aktfitas fisik sedang hingga berat. Sebagian subyek bekerja sebagai buruh tani, pemahat, dan lain-lain. Untuk mencapai tempat kerja, beberapa subyek mengaku harus berjalan kaki. Berjalan kaki merupakan salah satu aktifitas fisik yang dapat menurunkan resiko terjadinya hipertensi. Kebiasaan berolahraga dapat menurunkan tekanan sistolik maupun diastolik pada pasien hipertensi mencapai $7 / 6 \mathrm{mmHg}^{28}$

\section{SIMPULAN DAN SARAN}

Berdasarkan hasil penelitian tentang tingkat kepatuhan pengobatan dan gaya hidup sehat pasien hipertensi di wilayah kerja Puskesmas Tegallalang I, Gianyar, dapat disimpulkan jumlah subyek penelitian yang berjenis kelamin laiki-laki sebesar 56,1\% sedangkan perempuan 43,9\%, dengan subyek terbanyak pada kelompok umur 35-44 tahun. Sebagian besar pasien memiliki riwayat keluarga yang positif hipertensi, dan tidak memiliki penyakit penyerta. Sebagian besar subyek penelitian memiliki tingkat kepatuhan rendah (87,8\%), sedangkan 12,2\% subyek penelitian memiliki tingkat kepatuhan sedang. Sebesar 39\% subyek mengalami penurunan jumlah konsumsi rokok, sebesar 4,9\% mengalami penurunan konsumsi alkohol, sebesar 36,6\% mengalami penurunan konsumsi kopi, sebesar 4,9\% mengalami penurunan durasi menonton TV, sebesar 31,7\% mengalami peningkatan jumlah berolahraga dalam satu minggu, dan 34,1\% mengalami peningkatan durasi berolahraga.

Melihat proporsi penderita hipertensi pada kelompok umur 20-44 tahun yang sebagian besar memiliki tingkat kepatuhan rendah, hal ini sebaiknya menjadi acuan bagi Puskesmas Tegallalang I, dalam hal ini Program Promosi Kesehatan, untuk mengedukasi masyarakat mengenai pengobatan hipertensi serta komplikasi yang ditimbulkan jika hipertensi tidak dikontrol. Selain itu, perlu dilakukan komunikasi, informasi, dan edukasi (KIE) yang menitikberatkan pada kepatuhan pengobatan hipertensi dan perubahan gaya hidup bagi setiap pasien hipertensi, yang 
dalam hal ini termasuk dalam Program Penanggulanan Penyakit.

\section{DAFTAR PUSTAKA}

1. Suheil SJ. Risk factors for hypertension among urban males in Mombasa Kenya. Official Publication of the Tanzania Medical Students' Association. 2008.

2. U.S. Department Of Health And Human Services. The Seventh Report of the Joint National Committee on Prevention, Detection, Evaluation, and Treatment of High Blood Pressure. U.S. : U.S. Department Of Health And Human Services. 2004.

3. Supplement to JAPI. Epidemiology of Hypertension. JAPI. 2013 : vol.61.

4. Gillespie CD, Hurvitz KA. Prevalence of hypertension and controlled hypertension united states, 2007-2010. Morbidity and Mortality Weekly Report (MMWR). 2013 : 62(03) : 144-148.

5. Riskesdas. Penyakit Tidak Menular, in: Riskesdas 2013. Jakarta : Bakti Husada. 2013 : 88-90.

6. Puskemas Tegallalang I. Laporan profil Puskesmas Tegallalang I 2013. Bali : Gianyar. 2013.

7. Puskemas Tegallalang I. PTP Puskesmas Tegallalang I 2014. Bali : Gianyar. 2014.

8. Oparil S, Zaman MA, Calhoun DA. Pathogenesis of hypertension. Ann Intern Med. 2003 : 139 : 761-776.

9. Yadav S, Boddula R, Genitta G, Bhatia V, Bansal $B$, Kongara $S$, et al. prevalence and risk factors of pre-hypertension and hypertension in an affluent north Indian population. Indian J Med Res. 2008 : 128 : 712-720.

10. Sigarlaki HJO. Karakteristik dan faktor berhubungan dengan hipertensi di desa Bocor, kecamatan Bulus Pesantren, kabupaten Kebumen, Jawa Tengah, tahun 2006. Makara. $2006:$ 10(2) : 78-88.

11. Aziz AM, Ibrahim MI. Medication noncompliance - a thriving problem. Med J Malaysia. 1999 : 54(2) : 192-199.
12. Khalil SA, Elzubier AG. Drug compliance among hypertensive patients in Tabuk, Saudi Arabia. J Hypertens. 1997 : 15(5) : 561-565.

13. Rizzo JA, Simons WR. Variations in compliance among hypertensive patients by drug class: implications for health care costs. Clin Ther. 1997 : 19(6) : 1446-1457.

14. Snedecor GW, Cochran WG. Statictical Methods. Edisi ke enam. Ames: Lowa State University Press. 1967.

15. Laurent S, Cockcroft J, van Bortel L, et al.Expert consensus document on arterial stiffness: methodological issues and clinical applications.Eur. Heart J. 2006 : 27 : 25882605.

16. Mimran A, Ribstein J, Jover B. Aging and sodium homeostasis.Kidney Int. 1992 : 37 : S107-S113.

17. Kasper DL, Fauci AS, Longo DL, Braunwald E, Hauser SL, Jameson JL. Harrison's principles of internal medicine. $16^{\text {th }}$ edition. New York: McGraw-Hill. 2005.

18. Savoldelli VK, Gillaizeau F, Pouchot J, Lenain $E$, Vinay NP, Pouin PP, et al. Validation of a French version of the 8-item morisky medication adherence scale in hypertensive adults. The Journal of Clinical Hypertension. 2012 : 14(7) : 429-434.

19. Almas A, Hameed A, Ahmed B, Islam M. Compliance to antihypertensive therapy. JCPSP. 2006 : 16 : 23-26.

20. Jin J, Grant ES, Vernon MS, Shu C. Factors affecting therapeutic compliance: A review from the patient's perspective. Ther Clin Risk Manag.2008 : 4(1) : 269-286.

21. Doggrell, Sheila. Adherence to medicines in the older-aged with chronic conditions: does an intervention concerning adherence by an allied health professional help? Australia : Drugs and Aging. $2010: 27(3):$ 239-254.

22. Park DC, Hertzog G, Leventhal $H$ et al. Medicine adherence in rheumatoid arthritis patients: older is wiser. J Am Geriatric Soc. 1999 : 47 : 172-183.

23. Monane $\mathrm{M}$, Bohn RL, Gurwitz JH et al. Compliance with antihypertensive therapy among elderly Medicaid enrolees: the roles of age, gender, and race. Am J Public Health. $1996: 86: 1805-1808$. 
24. Benner JS, Glynn RJ, Mogun H et al. Longterm persistence in use of statin therapy in elderly patients. JAMA. 2002 : $288:$ 455-461.

25. Joho $A A$. Factors affecting treatment compliance among hypertension patients in three district hospitals - dar es salaam. Msc Nursing (critical care \& trauma) dissertation. Muhimbili University of Health and Allied Sciences (MUHAS). 2012.

26. Jenner DA, Puddey IB, Beilin L, et al. Lifestyle- and occupation-related changes in blood pressure over a six-year period in a cohort of working men. J Hypertens Suppl. 1988 : 6 : S605-S607.

27. Klag MJ, Wang NY, Meoni LA, et al.Coffee intake and risk of hypertension: The Johns Hopkins Precursors Study. Arch Intern Med. 2002 : 162 : 657-662.

28. Sharman JE, Stowasser M. Position statement on exercise and hypertension. Journal of Science and Medicine in Sport. 2009;12:252-257 